\title{
Bioinformatics analysis to screen key genes implicated in the differentiation of induced pluripotent stem cells to hepatocytes
}

\author{
RUI LIN*, YUFENG WANG* ${ }^{*}$, KUN JI, ZHONGYAN LIU, SHUAI XIAO, \\ DEHUA ZHOU, QUANNING CHEN and BAOMIN SHI \\ Department of General Surgery, Tongji Hospital, School of Medicine, Tongji \\ University Medical School, Shanghai 200065, P.R. China
}

Received February 1, 2016; Accepted January 27, 2017

DOI: $10.3892 / \mathrm{mmr} .2018 .8385$

\begin{abstract}
Due to the lack of potential organs, hepatocellular transplantation has been considered for treating end-stage liver disease. Induced pluripotent stem cells (iPSCs) are reverted from somatic cells and are able to differentiate into hepatocytes. The present study aimed to investigate the mechanisms underlying iPSC differentiation to hepatocytes. GSE66076 was downloaded from the Gene Expression Omnibus; this database includes data from 3 undifferentiated (T0), 3 definitive endoderm (T5), and 3 early hepatocyte (T24) samples across hepatic-directed differentiation of iPSCs. Differentially expressed genes (DEGs) between T0 and T5 or T24 samples were identified using the linear models for microarray data package in Bioconductor, and enrichment analyses were performed. Using the weighted correlation network analysis package in R, clusters were identified for the merged DEGs. Cytoscape was used to construct protein-protein interaction (PPI) networks for DEGs identified to belong to significant clusters. Using the ReactomeFI plugin in Cytoscape, functional interaction (FI) networks were constructed for the common genes. A total of 433 and 1,342 DEGs were identified in the T5 and T24 samples respectively, compared with the T0 samples. Blue and turquoise clusters were identified as significant gene clusters. In the PPI network for DEGs in the blue cluster, the key node fibroblast growth factor 2 (FGF2) could interact with bone morphogenetic protein 2 (BMP2). Cyclin-dependent kinase 1 (CDK1) was demonstrated to have the highest degree (degree=71) in the PPI
\end{abstract}

Correspondence to: Dr Quanning Chen or Dr Baomin Shi, Department of General Surgery, Tongji Hospital, School of Medicine, Tongji University Medical School, 389 Xincun Road, Shanghai 200065, P.R. China

E-mail: quanning_chen@sina.com

E-mail: baomin_shi@163.com

"Contributed equally

Key words: induced pluripotent stem cells, differentially expressed genes, weighted correlation network analysis, protein-protein interaction network, functional interaction network network for DEGs in the turquoise cluster. Enrichment analysis for the common genes, including hepatocyte nuclear factor $4 \alpha$ (HNF4A) and epidermal growth factor $(E G F)$, in the FI network indicated that $E G F$ and $F G F 2$ were enriched in the Ras and Rap1 signaling pathways. The present results suggest that $F G F 2, B M P 2, C D K 1, H N F 4 A$ and $E G F$ may participate in the differentiation of iPSCs into hepatocytes.

\section{Introduction}

Induced pluripotent stem cells (iPSCs), which are reverted from somatic cells via nuclear transfer and transcription factor-based reprogramming, are pluripotent stem cells that are able to differentiate into all cell types (1). They are successfully derived from somatic cells through viral transduction using the transcription factors sex-determining region Y-box 2, octamer-binding transcription factor 4 (Oct4), and either NANOG and lineage protein 28 (2) or $c-M Y C$ and Krüppel-like factor $4(3,4)$. The treatment of end-stage liver disease is severely impaired by the shortage of potential organs, therefore, hepatocellular transplantation substituting for whole organ transplant may hold potential as an alternative treatment strategy (5). Similar to embryonic stem cells (ESCs), iPSCs exhibit pluripotent properties and are able to differentiate into all cell lineages in vitro, including hepatocytes, suggesting that iPSCs may be a valuable cell source for hepatocellular transplantation $(6,7)$.

Several studies have investigated the mechanisms underlying differentiation of PSCs. The expression of the hepatic marker albumin has been reported to contribute to the efficient differentiation of iPSCs to hepatocyte-like cells (8). Transforming growth factor- $\beta$ has been revealed to correlate with the differentiation of iPSCs into functional endothelial cells, whereas the phosphatase and tensin homolog/Akt pathway targeted by microRNA (miR)-21 can assist the endothelial differentiation of iPSCs (9). E-cadherin and several other crucial cell adhesion molecules, including classic cadherins, heparin sulfate proteoglycans, members of the immunoglobulin (IgG) superfamily and integrins, have been demonstrated to regulate the differentiation and survival of human PSCs, including human ESCs and iPSCs $(10,11)$. Through activating mesenchymal-to-epithelial transition, hepatocyte nuclear factor $4 \alpha$ (HNF4A) may be implicated in the generation of hepatocytes from human ESC-derived hepatoblasts, which may 
represent a favorable pathway for the efficient differentiation of human ESCs and iPSCs into functional hepatocytes (12). Bone morphogenetic protein $(B M P)$ is regulated by Brachyury and caudal-related homeobox 2 (CDX2), and mainly promotes mouse and human PSC differentiation to mesoderm, not trophoblasts (13). However, the exact mechanisms guiding iPSC differentiation into hepatocytes remain to be elucidated.

Wilson et al (14) investigated the differentially expressed genes (DEGs) in iPSCs derived from patients with liver disease and healthy subjects upon in vitro differentiation to hepatocytes, and identified 419 DEGs at false discovery rate (FDR) $<0.25$ and $85 \mathrm{DEGs}$ at FDR $<0.1$. In the present study, using the more restrictive thresholds of adjusted P-value, i.e. FDR $<0.01$ and $\mid \log _{2}$ fold change $(F C) \mid \geq 2$, the DEGs between undifferentiated samples and definitive endoderm or early hepatocyte samples were identified, and their potential functions were predicted using enrichment analyses. Subsequently, the DEGs between the two groups were merged, and weighted correlation network analysis (WGCNA) was performed to identify gene clusters for the merged DEGs. Furthermore, the protein-protein interaction (PPI) networks for the DEGs belonging to the significant gene clusters were constructed, the common genes between the two comparison groups were identified, and their functional interaction (FI) network was analyzed.

\section{Materials and methods}

Microarray data. The GSE66076 expression profile (http://www. ncbi.nlm.nih.gov/geo/query/acc.cgi?acc=GSE 66076) deposited by Wilson et al (14), was downloaded from the National Center for Biotechnology Information Gene Expression Omnibus database, which was based on the GPL6244 [HuGene-1_0-st] Affymetrix Human Gene 1.0 ST Array [transcript (gene) version] platform. To study the differentiation mechanisms of iPSCs to hepatocytes, iPSCs across three stages of hepatic-directed differentiation were selected from GSE66076, including 3 undifferentiated (T0), 3 definitive endoderm (T5), and 3 early hepatocyte (T24) samples.

Data preprocessing and DEG screening. Following the download of GSE66076, raw data was preprocessed with background correction, normalization and expression calculation by Oligo package (15) in Bioconductor. The org.Hs.eg.db (16) and hugene10sttranscriptcluster.db (17) annotation packages were used to transform probe identifications (IDs) into gene symbols. For one gene symbol corresponding to several probe IDs, the mean value of probes was used as the final gene expression value.

The linear models for microarray data (limma) package (18) in Bioconductor was applied to identify the DEGs between T0 and T5 or T24 samples. The P-values for the DEGs were calculated using the t-test method in the limma package and were then adjusted using the method described by Benjamini and Hochberg (19). An FDR $<0.01$ and $\mid \log _{2} \mathrm{FCl} \geq 2$ were considered as the thresholds for significance.

Functional and pathway enrichment analysis. The ToppGene database (https://toppgene.cchmc.org/) (20) integrates pathway information in BioSystems [including BioCyc, Kyoto Encyclopedia of Genes and Genomes (KEGG), REACTOME, WikiPathways], GenMAPP, MSigDB C2 (including BioCarta,
SigmaAldrich and Signaling Gateway), PantherDB, Pathway Ontology and Small Molecule Pathway Database databases, and can be used for functional and pathway enrichment analyses. Gene Ontology (GO, http://www.geneontology.org/) describes functions of genes and their products in molecular function (MF), biological process (BP) and cellular component (CC) aspects (21). The KEGG (http://www.genome. $\mathrm{jp} / \mathrm{kegg} /$ ) database integrates chemical, genomic and systemic functional information of biological systems (22). Combined with the ToppGene database, GO functional and KEGG pathway enrichment analyses were carried out for the DEGs between $\mathrm{T} 0$ and $\mathrm{T} 5$ samples, as well as those between $\mathrm{T} 0$ and T24 samples. An FDR $\leq 0.05$ and the involvement of at least 2 genes were used as the cut-off criteria.

WGCNA analysis. WGCNA is usually applied for identifying highly correlated gene clusters, for summarizing the clusters using the intramodular hub gene or module eigengene, for linking modules to other modules and to external sample characteristics, and for calculating module membership measures (23). The DEGs in the T0 vs. T5 and the T0 vs. T24 comparison groups were merged. Subsequently, the WGCNA package (23) in $\mathrm{R}$ was used to identify gene clusters for the merged DEGs. The clusters with $\mid$ Correlation coefficient $\mid>0.8$ and $\mathrm{P}<0.05$ were identified as significant gene clusters.

PPI network construction. The Search Tool for the Retrieval of Interacting Genes (STRING) database contains easily accessed and uniquely comprehensive experimental and predicted interaction information (24). The STRING database (http://string-db. org/) (24) was used to identify PPI relationships among the significant gene clusters, and a required confidence (combined score) $>0.7$ was set as the cut-off criterion. Subsequently, the PPI network was visualized using the Cytoscape software (http://www.cytoscape.org/) (25). The proteins in the network were represented as nodes, whereas their degrees corresponded to the number of edges associated with that node.

Common gene analysis. The Venny 2.0 online tool (http://bioinfogp.cnb.csic.es/tools/venny/index.html) was used to identify the common genes between the two comparison groups. The gene FI network was constructed by merging interactions predicted using a machine learning approach with interactions extracted from human curated pathways (24). ReactomeFI can be used for network-based data analysis through the highly reliable Reactome FI network (26). According to the expression profiles data, the ReactomeFI plugin (26) in Cytoscape was used to analyze the FI network for the common genes.

\section{Results}

$D E G$ analysis. Using a threshold of $\mathrm{FDR}<0.01$ and $\mid \log _{2} \mathrm{FCl} \geq 2$, the DEGs between T0 and T5 or T24 samples were investigated. Compared with T0 samples, 433 (including 268 upregulated and 165 downregulated genes) and 1,342 (including 729 upregulated and 613 downregulated genes) DEGs were identified in the T5 and T24 samples, respectively.

Functional and pathway enrichment analysis. The upregulated genes in T5 samples were significantly enriched in 
Table I. Top 3 functions and pathways enriched for differentially expressed genes in T5 samples.

\begin{tabular}{|c|c|c|c|c|c|}
\hline Category & ID & Description & FDR & Gene no. & Gene symbol \\
\hline \multicolumn{6}{|l|}{ Upregulated } \\
\hline \multirow[t]{3}{*}{ GO_BP } & GO:0009888 & tissue development & $2.70 \mathrm{E}-13$ & 72 & HHEX, ARHGAP24, FOXQ1_.... \\
\hline & GO:0072359 & $\begin{array}{l}\text { circulatory system } \\
\text { development }\end{array}$ & $2.88 \mathrm{E}-11$ & 46 & EPHB3, HHEX, ARHGAP24..... \\
\hline & GO:0072358 & $\begin{array}{l}\text { cardiovascular system } \\
\text { development }\end{array}$ & $2.88 \mathrm{E}-11$ & 46 & ADAM19, GATA4, GATA6..... \\
\hline \multirow[t]{3}{*}{ GO_CC } & GO:0005615 & extracellular space & $2.85 \mathrm{E}-07$ & 47 & PRSS2, RELN, ABCA1..... \\
\hline & GO:0002116 & $\begin{array}{l}\text { semaphorin receptor } \\
\text { complex }\end{array}$ & $2.12 \mathrm{E}-04$ & 4 & NRP2, NRP1, PLXNA2, PLXNA4 \\
\hline & GO:0009897 & $\begin{array}{l}\text { external side of } \\
\text { plasma membrane }\end{array}$ & $5.50 \mathrm{E}-04$ & 15 & ABCA1, DLK1, ITGA5 ..... \\
\hline \multirow[t]{3}{*}{ GO_MF } & GO:0060089 & $\begin{array}{l}\text { molecular transducer } \\
\text { activity }\end{array}$ & $2.50 \mathrm{E}-04$ & 50 & 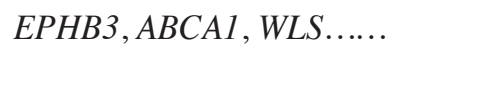 \\
\hline & GO:0004871 & signal transducer activity & $2.50 \mathrm{E}-04$ & 50 & $H N F 4 A, I L 18 R 1, R X R G \ldots \ldots$. \\
\hline & GO:0004872 & receptor activity & $7.51 \mathrm{E}-04$ & 46 & SORCS1, FZD4, FZD8..... \\
\hline \multirow[t]{3}{*}{$\begin{array}{l}\text { KEGG } \\
\text { pathway }\end{array}$} & 119526 & $\begin{array}{l}\text { other semaphorin } \\
\text { interactions }\end{array}$ & $5.42 \mathrm{E}-03$ & 5 & SEMA6D, PLXNA2, SEMA5A..... \\
\hline & 576262 & $\begin{array}{l}\text { extracellular matrix } \\
\text { organization }\end{array}$ & $1.10 \mathrm{E}-02$ & 15 & PRSS2, MATN3, ITGA5_.... \\
\hline & 198832 & adipogenesis & $5.42 \mathrm{E}-03$ & 11 & SPOCK1, CYP26A1, GATA4..... \\
\hline Downregulated & GO:0007267 & cell-cell signaling & $1.20 \mathrm{E}-02$ & 28 & SOX2, LPAR3, SFRP $2 \ldots \ldots$. \\
\hline \multirow{2}{*}{ GO_BP } & GO:0007268 & synaptic transmission & $2.03 \mathrm{E}-02$ & 20 & LPAR3, CHRNA9, RASGRF2.. \\
\hline & GO:0045766 & $\begin{array}{l}\text { positive regulation of } \\
\text { angiogenesis }\end{array}$ & 4.82E-02 & 7 & FLT1, SFRP 2, VASH $2 \ldots \ldots$. \\
\hline \multirow{3}{*}{ GO_CC } & GO:0045202 & synapse & $1.42 \mathrm{E}-03$ & 18 & NMNAT2, CHRNA9, GAP43..... \\
\hline & GO:0097060 & synaptic membrane & $1.42 \mathrm{E}-03$ & 11 & CHRNA9, GABRQ, CNKSR2..... \\
\hline & GO:0045211 & postsynaptic membrane & $1.42 \mathrm{E}-03$ & 10 & LRRTM3, VRL3, MET ..... \\
\hline
\end{tabular}

GO, Gene Ontology; KEGG, Kyoto Encyclopedia of Genes and Genomes; BP, biological process; CC, cellular component; MF, molecular function; FDR, false discovery rate.

567 GO_BP terms, 12 GO_CC terms, 29 GO_MF terms and 7 KEGG pathways. The top 3 functions and pathways are presented in Table I, including tissue development (GO_BP, FDR=2.70E-13), extracellular space (GO_CC, $\mathrm{FDR}=2.85 \mathrm{E}-07)$, molecular transducer activity (GO_MF, FDR $=2.50 \mathrm{E}-04$; which involved $H N F 4 A$ ) and extracellular matrix organization (pathway, FDR=1.10E-02). Meanwhile, the downregulated genes in T5 samples were significantly enriched in 3 GO_BP terms and 15 GO_CC terms, including cell-cell signaling (GO_BP, FDR=1.20E-02) and synapse (GO_CC, FDR=1.42E-03).

Upregulated genes in T24 samples were significantly enriched in 1,145 GO_BP terms, 88 GO_CC terms, 146 GO_MF terms and 142 KEGG pathways. The top 3 functions and pathways are presented in Table II, including extracellular matrix organization (GO_BP, FDR=1.39E-21), extracellular space (GO_CC, FDR=8.05E-44), receptor binding (GO_MF, FDR=1.16E-11; which involved HNF4A) and complement and coagulation cascades (pathway, FDR=1.27E-16). Meanwhile, downregulated genes in T24 samples were significantly enriched in 317 GO_BP terms, 70 GO_CC terms, 41 GO_MF terms and 152 KEGG pathways. The top 3 functions and pathways are presented in Table II, including cell cycle (GO BP, FDR=1.55E-51), chromosome (GO_CC, FDR=1.18E-44), ribonucleotide binding (GO_MF, FDR=1.40E-07) and cell cycle (pathway, FDR=1.67E-49).

WGCNA analysis. The DEGs in the T0 vs. T5 and T0 vs. T24 comparison groups were merged and 1,569 DEGs were obtained. Based on WGCNA, 3 gene clusters were identified, including blue (correlation coefficient, -0.98; $\mathrm{P}=3.07 \mathrm{E}-06$ ), green (correlation coefficient, $0.25 ; \mathrm{P}=5.16 \mathrm{E}-01$ ), and turquoise (correlation coefficient, 0.89; $\mathrm{P}=1.14 \mathrm{E}-03$ ) clusters (Fig. 1). Blue and turquoise gene clusters were significant.

The 504 DEGs in the blue cluster were significantly enriched in 274 GO_BP terms, 36 GO_CC terms and 33 KEGG pathways. The top 5 functions and pathways are presented in Table III, including regulation of multicellular organismal development (GO_BP; FDR=5.97E-06; which involved BMP2), chromosome (GO_CC, FDR=3.79E-03) and systemic lupus erythematosus (pathway, FDR=1.00E-03). Meanwhile, the 833 DEGs in the turquoise cluster were significantly enriched in 802 GO_BP terms, 87 GO_CC terms, 78 GO_MF terms and 166 KEGG pathways. The 
Table II. Top 3 functions and pathways enriched for differentially expressed genes in T24 samples.

\begin{tabular}{|c|c|c|c|c|c|}
\hline Category & ID & Description & FDR & Gene no. & Gene symbol \\
\hline \multicolumn{6}{|l|}{ Upregulated } \\
\hline \multirow[t]{3}{*}{ GO_BP } & GO:0030198 & $\begin{array}{l}\text { extracellular matrix } \\
\text { organization }\end{array}$ & $1.39 \mathrm{E}-21$ & 66 & $T T R, F A P, M F I 2 \ldots \ldots$ \\
\hline & GO:0043062 & $\begin{array}{l}\text { extracellular structure } \\
\text { organization }\end{array}$ & $1.39 \mathrm{E}-21$ & 66 & FBN1, EFEMP1, HPN..... \\
\hline & GO:0009611 & response to wounding & $6.97 \mathrm{E}-19$ & 122 & CFH, EPHX2, SERPINA3 ..... \\
\hline \multirow[t]{3}{*}{ GO_CC } & GO:0005615 & extracellular space & $8.05 \mathrm{E}-44$ & 165 & $A B C A 1, I L 32, F S T L 3 \ldots \ldots$. \\
\hline & GO:0031012 & extracellular matrix & $1.34 \mathrm{E}-18$ & 63 & SERPINF 1, CHI3L1, F2 ..... \\
\hline & GO:0005578 & $\begin{array}{l}\text { proteinaceous extracellular } \\
\text { matrix }\end{array}$ & $2.12 \mathrm{E}-17$ & 55 & SERPINA1, FBN1, EFEMP $1 \ldots \ldots$ \\
\hline \multirow[t]{3}{*}{ GO_MF } & GO:0005102 & receptor binding & $1.16 \mathrm{E}-11$ & 113 & 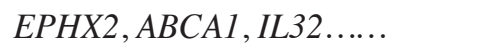 \\
\hline & GO:1901681 & sulfur compound binding & $6.03 \mathrm{E}-09$ & 34 & $C F H, A C A D L, H N F 4 A \ldots \ldots$ \\
\hline & GO:0050839 & $\begin{array}{l}\text { cell adhesion molecule } \\
\text { binding }\end{array}$ & $7.59 \mathrm{E}-09$ & 29 & $N D R G 1, F G A, F G B \ldots \ldots$ \\
\hline \multirow[t]{3}{*}{$\begin{array}{l}\text { KEGG } \\
\text { pathway }\end{array}$} & 83073 & $\begin{array}{l}\text { complement and } \\
\text { coagulation cascades }\end{array}$ & $1.27 \mathrm{E}-16$ & 28 & $C F H, F 2, F 3 \ldots \ldots$ \\
\hline & 198880 & $\begin{array}{l}\text { complement and } \\
\text { coagulation cascades }\end{array}$ & $7.64 \mathrm{E}-15$ & 23 & SERPINA1, FGB, PLG..... \\
\hline & M4470 & $\begin{array}{l}\text { extrinsic prothrombin } \\
\text { activation pathway }\end{array}$ & $7.08 \mathrm{E}-13$ & 12 & $F G B, F G G$, SERPINC1 ..... \\
\hline \multirow{3}{*}{$\begin{array}{l}\text { Downregulated } \\
\text { GO_BP }\end{array}$} & GO:0000278 & mitotic cell cycle & $8.81 \mathrm{E}-55$ & 141 & NUSAP1, CDKN3, KIF18A..... \\
\hline & GO:0007049 & cell cycle & $1.55 \mathrm{E}-51$ & 180 & BRIP1, MIS18BP1, CENPW..... \\
\hline & GO:0022402 & cell cycle process & $1.06 \mathrm{E}-48$ & 151 & CENPW, CENPE, CENPF ..... \\
\hline \multirow[t]{3}{*}{ GO_CC } & GO:0005694 & chromosome & $1.18 \mathrm{E}-44$ & 116 & NUSAP1, CHAF1B, MIS18BP1... \\
\hline & GO:0044427 & chromosomal part & $1.44 \mathrm{E}-36$ & 97 & CHAF $1 B$, MIS18BP $1, C E N P W \ldots$ \\
\hline & GO:0032993 & protein-DNA complex & $6.76 \mathrm{E}-32$ & 62 & MIS18BP1, CENPW, CENPE.... \\
\hline \multirow[t]{3}{*}{ GO_MF } & GO:0032559 & $\begin{array}{l}\text { adenyl ribonucleotide } \\
\text { binding }\end{array}$ & $1.40 \mathrm{E}-07$ & 94 & KIF18A, BRIP1, CENPE..... \\
\hline & GO:0005524 & ATP binding & $1.40 \mathrm{E}-07$ & 92 & ATAD5, MARK1, MCM2..... \\
\hline & GO:0030554 & adenyl nucleotide binding & $1.52 \mathrm{E}-07$ & 94 & MCM4, PFAS, MCM5..... \\
\hline KEGG & 530733 & cell cycle & $1.67 \mathrm{E}-49$ & 105 & KIF18A, PTTG1, MIS18BP1..... \\
\hline \multirow[t]{2}{*}{ pathway } & 105765 & cell cycle, mitotic & $1.57 \mathrm{E}-35$ & 81 & KIF18A, PTTG1, CENPE..... \\
\hline & 105750 & G2/M checkpoints & $7.54 \mathrm{E}-21$ & 24 & MCM2, МCM3, MCM4 ..... \\
\hline
\end{tabular}

GO, Gene Ontology; KEGG, Kyoto Encyclopedia of Genes and Genomes; BP, biological process; CC, cellular component; MF, molecular function; FDR, false discovery rate.

top 5 functions and pathways are presented in Table IV, including mitotic cell cycle [GO_BP; FDR=3.93E-28; which involved cyclin-dependent kinase $1(C D K 1)]$, extracellular space $\left(\mathrm{GO} \_\mathrm{CC}, \mathrm{FDR}=3.10 \mathrm{E}-23\right)$, receptor binding $\left(\mathrm{GO} \_\mathrm{MF}\right.$, $\mathrm{FDR}=2.47 \mathrm{E}-04$ ) and cell cycle (pathway, $\mathrm{FDR}=4.76 \mathrm{E}-16$; which involved $C D K 1$ ).

PPI network analysis for genes in the blue and turquoise clusters. The PPI network for DEGs in the blue cluster demonstrated 218 nodes and 388 interactions (Fig. 2). In the PPI network, fibroblast growth factor $2(\mathrm{FGF} 2$, degree $=14)$ and BMP2 (degree=12) were the nodes with the higher degrees, and FGF2 had interactions with BMP2 in the PPI network. Furthermore, the PPI network for DEGs in the turquoise cluster demonstrated 488 nodes and 1,803 interactions (Fig. 3).
Notably, CDK1 (degree=71) was the node with the highest degree in the PPI network.

Common gene analysis. A total of 202 common genes, including $H N F 4 A$, epidermal growth factor $(E G F)$ and $F G F 2$ were identified between the two comparison groups, of which 100 were upregulated and 102 were downregulated (Fig. 4). According to the expression profile data of the common genes, a gene FI network was constructed (Fig. 5A). The top 11 most significant pathways enriched for the genes in the FI network are presented in Fig. 5B, and include the Ras signaling pathway $(\mathrm{K})$, the Rap1 signaling pathway $(\mathrm{K})$ and actions of nitric oxide in the heart (B). Notably, EGF and FGF2 were enriched in the Ras $(\mathrm{K})$ and Rap1 signaling pathways $(\mathrm{K})$. 
Cluster dendrogram

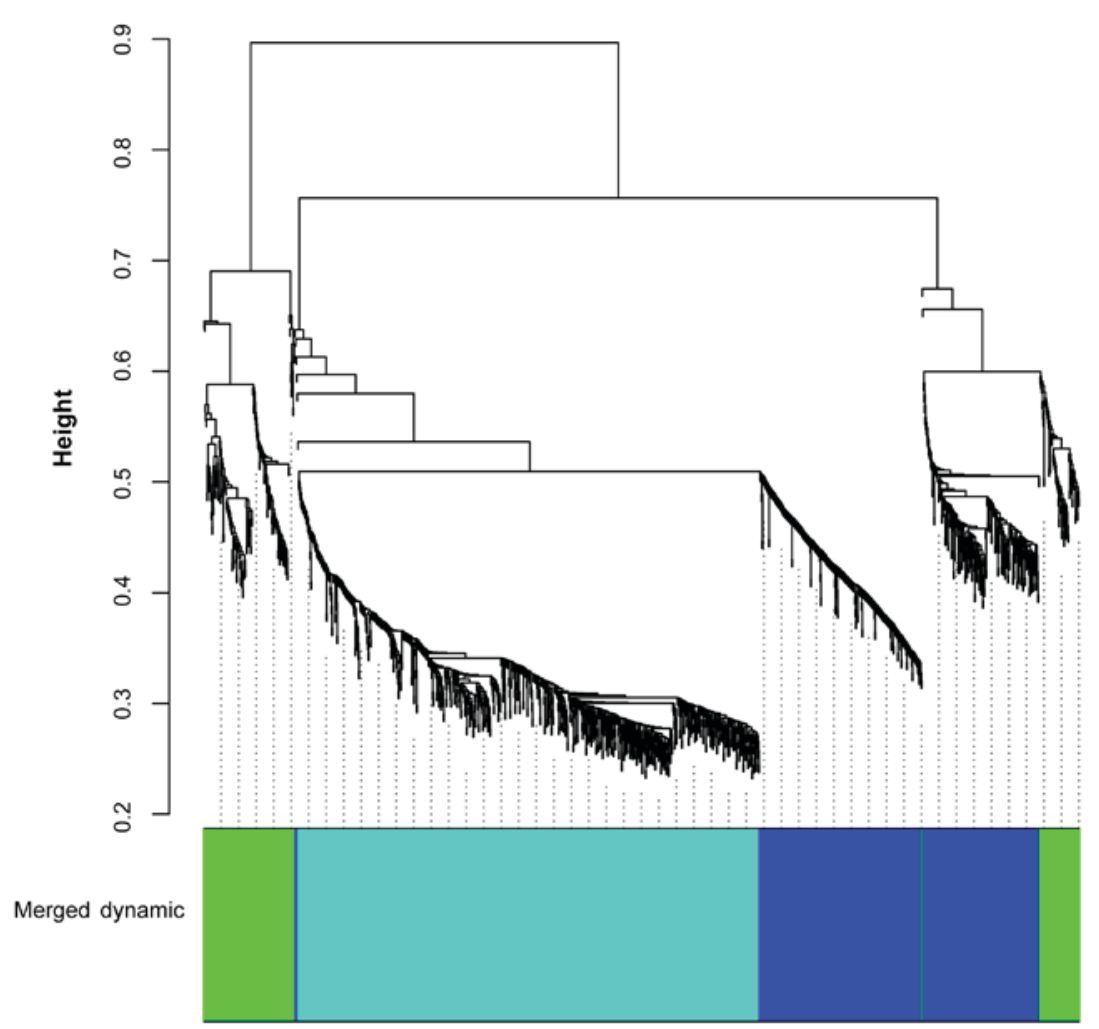

Figure 1. Dendrogram for identifying gene clusters for the merged differentially expressed genes using weighted correlation network analysis.

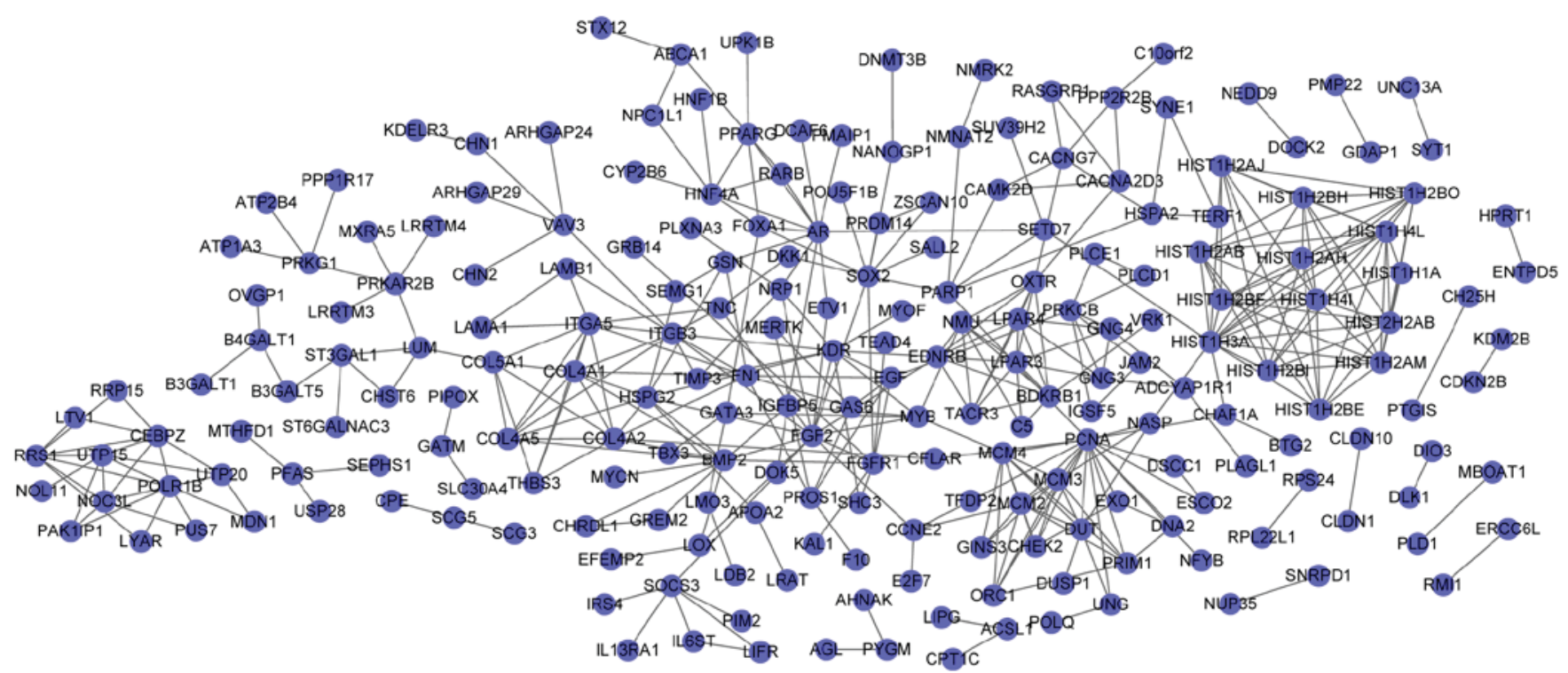

Figure 2. Protein-protein interaction network for differentially expressed genes in the blue cluster.

\section{Discussion}

In the present study, 433 DEGs were identified between the T5 and T0 samples, including 268 up- and 165 downregulated genes, whereas 1,342 DEGs were identified between the T24 and T0 samples, including 729 up- and 613 downregulated genes. Based on WGCNA, blue and turquoise clusters were identified as significant gene clusters. A total of 202 common genes, including 100 up- and 102 downregulated genes, were identified between the two comparison groups, and a gene FI network was constructed.

In the PPI network for DEGs in the blue cluster, upregulated FGF2 (degree $=14)$ and downregulated BMP2 (degree $=12$ ) were the nodes with the higher degrees. Exogenous $F G F 2$ has been reported to enhance the role of intracrine $F G F 2$ signaling in the maintenance of pluripotency; conversely, a downregulation 
Table III. Top 5 functions and pathways enriched for differentially expressed genes in the blue cluster.

\begin{tabular}{|c|c|c|c|c|c|}
\hline Category & ID & Description & FDR & Gene no. & Gene symbol \\
\hline \multirow[t]{5}{*}{ GO_BP } & GO:2000026 & $\begin{array}{l}\text { regulation of multicellular } \\
\text { organismal development }\end{array}$ & $5.97 \mathrm{E}-06$ & 78 & $C D K N 2 B, L P A R 3, R A M P 2 \ldots \ldots$ \\
\hline & GO:0001763 & $\begin{array}{l}\text { morphogenesis of a } \\
\text { branching structure }\end{array}$ & $1.17 \mathrm{E}-05$ & 24 & FOXA1, FGF2, FGFR1 ..... \\
\hline & GO:0048589 & developmental growth & 1.17E-05 & 30 & LPAR3, BCL11A, DRAXIN..... \\
\hline & GO:0061138 & $\begin{array}{l}\text { morphogenesis of a } \\
\text { branching epithelium }\end{array}$ & $1.17 \mathrm{E}-05$ & 23 & $F O X A 1, F G F 2, F G F R 1 \ldots \ldots$ \\
\hline & GO:0048754 & $\begin{array}{l}\text { branching morphogenesis } \\
\text { of an epithelial tube }\end{array}$ & $1.17 \mathrm{E}-05$ & 21 & $F O X A 1, F G F 2, C O L A A 1 \ldots \ldots$ \\
\hline \multirow[t]{5}{*}{ GO_CC } & GO:0044420 & $\begin{array}{l}\text { extracellular matrix } \\
\text { component }\end{array}$ & $1.46 \mathrm{E}-03$ & 15 & COL4A1, COLAA2, COLAA5...... \\
\hline & GO:0000785 & chromatin & 2.27E-03 & 26 & MCM2, HIST1H2AJ, HIST1H2AB..... \\
\hline & GO:0005604 & basement membrane & $2.36 \mathrm{E}-03$ & 12 & COL4A1, COLAA2, COLAA5..... \\
\hline & GO:0005694 & chromosome & 3.79E-03 & 40 & MCM2, MCM3, HIST1H4I..... \\
\hline & GO:0044427 & chromosomal part & $4.60 \mathrm{E}-03$ & 35 & MCM2, MCM3, HIST1H2AJ..... \\
\hline \multirow{5}{*}{$\begin{array}{l}\text { KEGG } \\
\text { pathway }\end{array}$} & 106540 & telomere maintenance & 7.80E-04 & 13 & HIST1H4I,HIST1H2AJ, HIST1H2AB.... \\
\hline & 366238 & amyloids & $9.81 \mathrm{E}-04$ & 13 & HIST1H4I, HIST1H2AJ, HIST1H2AB.... \\
\hline & 106548 & $\begin{array}{l}\text { packaging of telomere } \\
\text { ends }\end{array}$ & $9.81 \mathrm{E}-04$ & 10 & HIST1H4I, HIST1H2AJ, HIST1H2AB.... \\
\hline & 477134 & meiotic synapsis & $9.81 \mathrm{E}-04$ & 12 & HIST1H4I, HIST1H2AJ, HIST1H2AB... \\
\hline & 83122 & $\begin{array}{l}\text { systemic lupus } \\
\text { erythematosus }\end{array}$ & $1.00 \mathrm{E}-03$ & 16 & HLA-DOA, HIST1H4I, HIST1H2AJ...... \\
\hline
\end{tabular}

GO, Gene Ontology; KEGG, Kyoto Encyclopedia of Genes and Genomes; BP, biological process; CC, cellular component; FDR, false discovery rate.

of endogenous $F G F 2$ has been demonstrated during the differentiation of human ESCs, whereas its knockdown has been revealed to contribute to hESC differentiation $(27,28)$. It has previously been reported that FGF2 signaling controls BMP4-mediated hESCs differentiation by maintaining levels of $N A N O G$ via the mitogen-activated protein kinase kinase/extracellular signal-regulated kinase pathway (29). In the present study, functional enrichment of the DEGs in the blue cluster demonstrated that BMP2 was enriched in the regulation of multicellular organismal development. Previous studies have reported that $B M P 2$ may participate in hESC differentiation through the control of an important early commitment step, which may provide the route for differentiation of pluripotent cells into neural precursors (30). It has been revealed that $B M P-2 / 6$ was more successful in inducing hESCs differentiation than BMP-2 or BMP-6, and it was able to substitute these BMPs during in vitro differentiation guidance (31). In addition, the FGF pathway serves an important role in directing the $B M P 4$-induced generation of syncytiotrophoblasts from hESCs (32). These findings suggested that $F G F 2$ and $B M P 2$ may serve key roles in the differentiation of iPSCs. In the PPI network for DEGs in the blue cluster, FGF2 could interact with BMP2, suggesting that $F G F 2$ may participate in iPSC differentiation through interacting with $B M P 2$.

Upregulated CDK1 (degree=71) was the node with the highest degree in the PPI network for DEGs in the turquoise cluster. In human mesenchymal stem cells (MSCs), CDK1 activation has been reported to facilitate the differentiation of MSCs into osteoblasts by phosphorylating the enhancer of zeste homologue 2 at Thr 487 (33). Through promoting the binding between Oct4 and the trophectoderm marker $C D X 2, C D K 1$ has been demonstrated to prevent the generation of trophectoderm from ESCs and accordingly maintain stemness (34). CDK1 suppression conferred by p57, as well as the inhibition of the DNA damage response caused by p21, can trigger the differentiation of trophoblast stem cells into giant cells (35). $C D K 1 / 2$ have been considered critical for the regulation of self-renewal and lineage specification of hESCs (36). CDK1 expression has been reported to markedly decrease during ESC differentiation, whereas its knockdown reduced the colony formation potential and proliferation of ESCs, suggesting that $C D K 1$ may contribute to maintaining the self-renewing and unique undifferentiated state of mouse ESCs (37). In the present study, enrichment analysis for DEGs in the turquoise cluster revealed that $C D K 1$ was enriched in mitosis and cell cycle pathways. Therefore, it may be hypothesized that $C D K 1$ is involved in iPSC differentiation.

$H N F 4 A$ and EGF were common genes between the two comparison groups, as they were revealed to be consistently downregulated in T5 and T24 samples. HNF4A serves an important role in specifying hepatic progenitor cells from hPSCs, via establishing the expression of the transcription factor network regulating the initiation of 


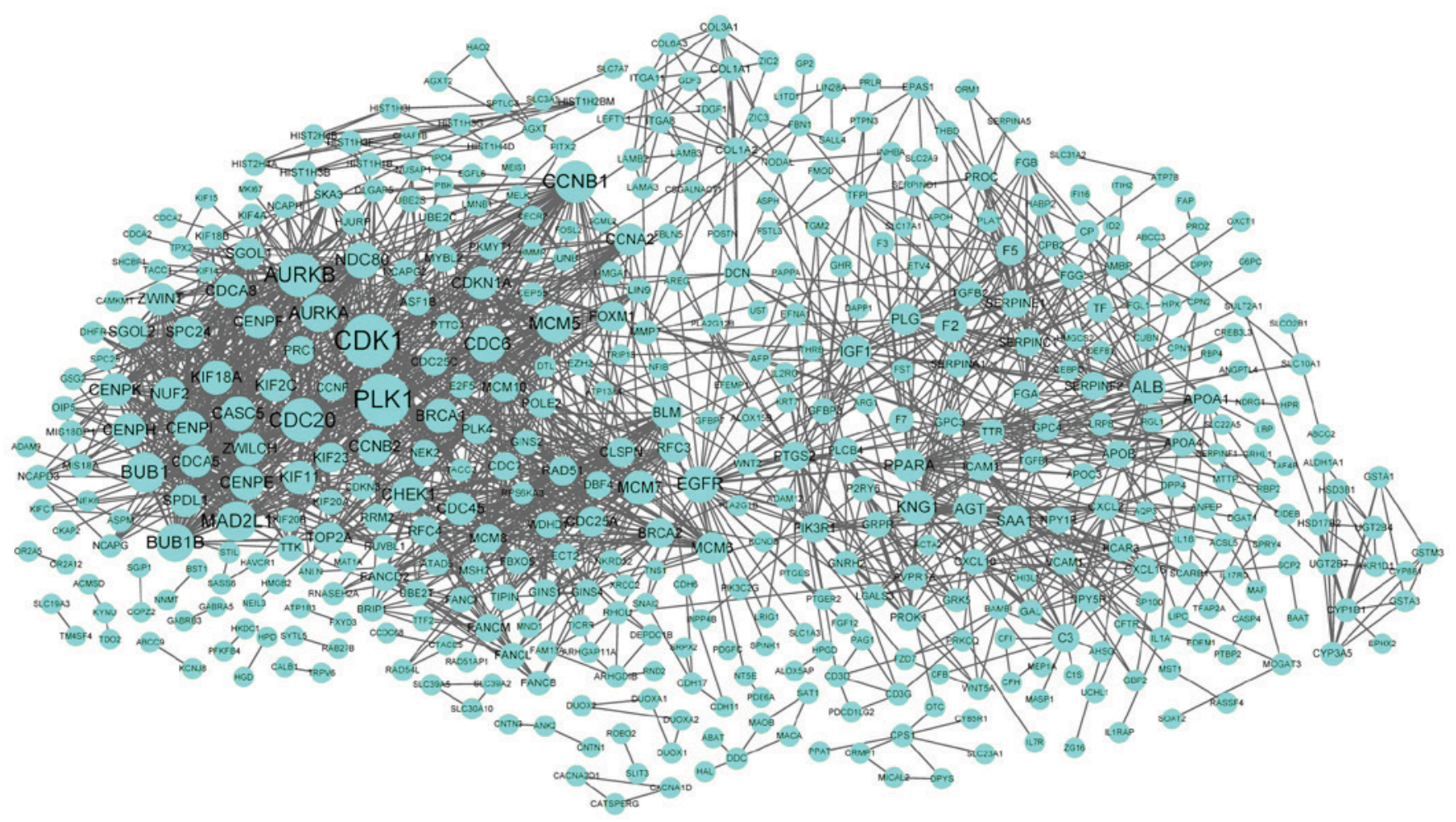

Figure 3. Protein-protein interaction network for differentially expressed genes in the turquoise cluster.
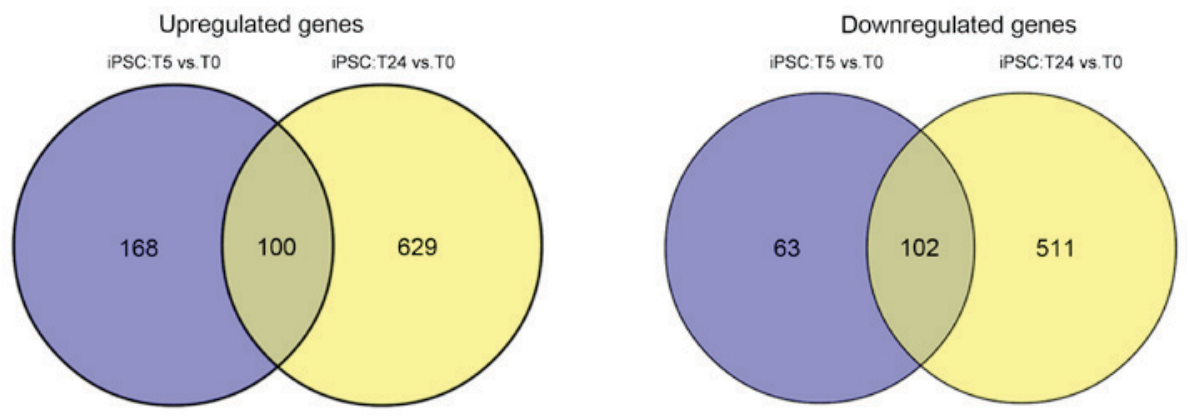

Figure 4. Venn diagram for identifying the common genes between the two comparison groups: T5 vs. T0 and T24 vs. T0.
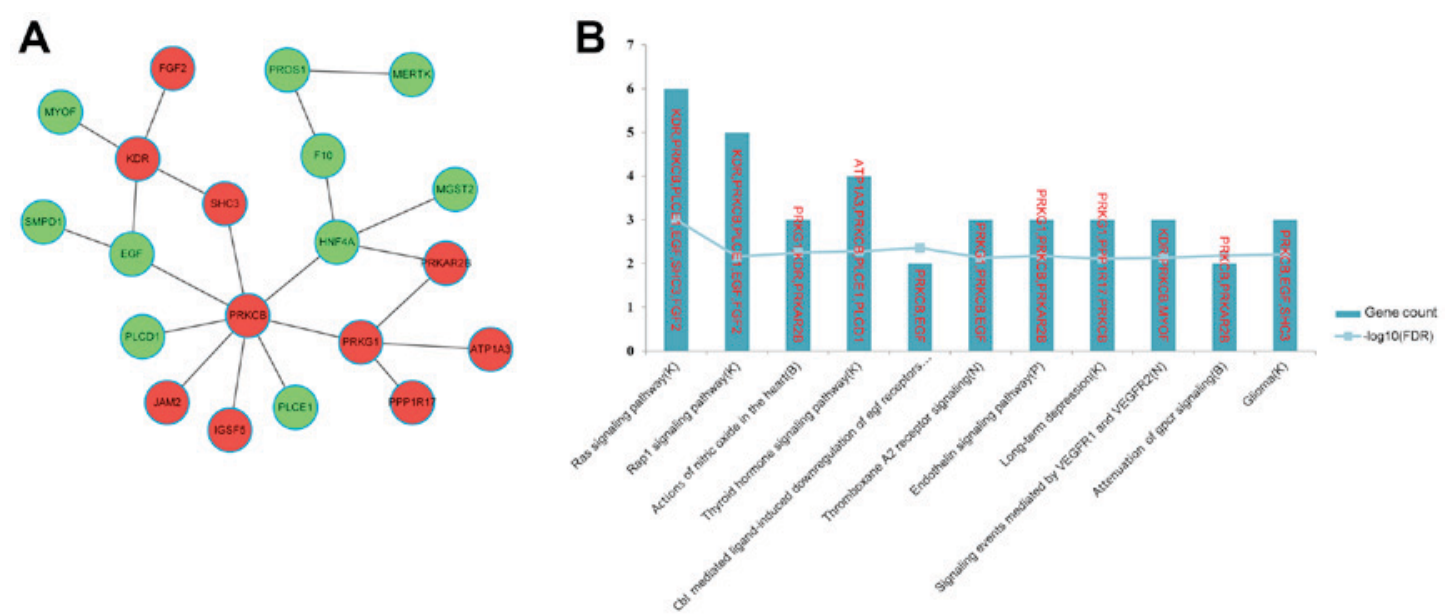

Figure 5. FI network for the common genes and the top 11 most significant pathways enriched for genes in the network. (A) FI network for the common genes. The red and green nodes represent up- and downregulated genes, respectively. (B) Top 11 most significant pathways enriched for the genes in the FI network. The $y$-axis represents the number of genes enriched in each pathway. The $\mathrm{x}$-axis represents the various pathways. Common symbols for the genes involved in each pathway are shown in red. The database sources of the various pathways are included in brackets. FI, functional interaction; C, CellMap; R, Reactome; K, Kyoto Encyclopedia of Genes and Genomes; N, National Cancer Institute Pathway Interaction Database; P, Panther; and B, BioCarta. 
Table IV. Top 5 functions and pathways enriched for differentially expressed genes in the turquoise cluster.

\begin{tabular}{|c|c|c|c|c|c|}
\hline Category & ID & Description & FDR & Gene no. & Gene symbol \\
\hline \multirow[t]{5}{*}{ GO_BP } & GO:0000278 & mitotic cell cycle & $3.93 \mathrm{E}-28$ & 127 & NUSAP1, KIF18A, MIS18BP1..... \\
\hline & GO:0007067 & mitotic nuclear division & $1.58 \mathrm{E}-26$ & 77 & CENPW, SPC25, SGOL1..... \\
\hline & GO:0000280 & nuclear division & $1.61 \mathrm{E}-25$ & 90 & FANCD2, NDC80, MKI67..... \\
\hline & GO:1903047 & mitotic cell cycle process & $8.19 \mathrm{E}-25$ & 111 & MCM10, RRM2, EZH2..... \\
\hline & GO:0048285 & organelle fission & 7.14E-24 & 90 & $S P C 24, R U V B L 1, T P X 2 \ldots \ldots$ \\
\hline \multirow[t]{5}{*}{ GO_CC } & GO:0005615 & extracellular space & $3.10 \mathrm{E}-23$ & 141 & SERPINA3, FSTL3, ACTA2 $\ldots \ldots$. \\
\hline & GO:0000775 & $\begin{array}{l}\text { chromosome, centromeric } \\
\text { region }\end{array}$ & $1.99 \mathrm{E}-16$ & 39 & MISI8BP1, CENPW, HJURP..... \\
\hline & GO:0005694 & chromosome & $9.93 \mathrm{E}-16$ & 90 & CENPW, HJURP, SPC25..... \\
\hline & GO:0000793 & condensed chromosome & $3.71 \mathrm{E}-15$ & 40 & SPC24,CDCA5, CENPK..... \\
\hline & GO:0000779 & $\begin{array}{l}\text { condensed chromosome, } \\
\text { centromeric region }\end{array}$ & $7.92 \mathrm{E}-15$ & 28 & $B U B 1, B U B 1 B, K I F 2 C \ldots \ldots$ \\
\hline \multirow[t]{5}{*}{ GO_MF } & GO:0005102 & receptor binding & $2.47 \mathrm{E}-04$ & 100 & 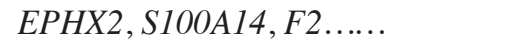 \\
\hline & GO:0030414 & peptidase inhibitor activity & $2.47 \mathrm{E}-04$ & 24 & SERPINA3, RPS6KA3, CD109...... \\
\hline & GO:0004867 & $\begin{array}{l}\text { serine-type endopeptidase } \\
\text { inhibitor activity }\end{array}$ & $2.47 \mathrm{E}-04$ & 17 & SERPINA3, CD109, AGT..... \\
\hline & GO:0004866 & $\begin{array}{l}\text { endopeptidase inhibitor } \\
\text { activity }\end{array}$ & $2.47 \mathrm{E}-04$ & 23 & SERPINA3, RPS6KA3, CD109... \\
\hline & GO:0061135 & $\begin{array}{l}\text { endopeptidase regulator } \\
\text { activity }\end{array}$ & $3.74 \mathrm{E}-04$ & 23 & AGT, AHSG,AMBP,SERPINA11.. \\
\hline KEGG & 530733 & cell cycle & $4.76 \mathrm{E}-16$ & 80 & KIF18A, MIS18BP1, HJURP..... \\
\hline \multirow[t]{4}{*}{ pathway } & 105765 & cell cycle, mitotic & $1.16 \mathrm{E}-14$ & 68 & KIF 18A, SPC25, MCM5..... \\
\hline & 83073 & $\begin{array}{l}\text { complement and } \\
\text { coagulation cascades }\end{array}$ & $1.44 \mathrm{E}-13$ & 26 & $F G B, F G G, S E R P I N C 1 \ldots \ldots$ \\
\hline & 105815 & mitotic prometaphase & $2.98 \mathrm{E}-12$ & 31 & KIF18A, SPC25, SGOL1..... \\
\hline & 198880 & $\begin{array}{l}\text { complement and } \\
\text { coagulation cascades }\end{array}$ & $8.46 \mathrm{E}-12$ & 21 & FGB, SERPINC1, C1S..... \\
\hline
\end{tabular}

GO, Gene Ontology; KEGG, Kyoto Encyclopedia of Genes and Genomes; BP, biological process; CC, cellular component; MF, molecular function; FDR, false discovery rate.

hepatocyte differentiation (38). The miR-122/forkhead box A1/HNF4A-positive feedback loop has been reported to promote maturation and differentiation of mouse ESCs into hepatocytes, via controlling the balance between epithelial-to-mesenchymal and mesenchymal-to-epithelial transition, as well as the balance between differentiation and proliferation $(39,40)$. Previous studies demonstrated that EGF promoted proliferation of mouse ESCs through $\mathrm{Ca}^{2+}$ influx, phospholipase C-protein kinase C, and p44/42 mitogen-activated protein kinases signaling pathways, via the phosphorylation of the EGF receptor $(41,42)$. Heparin-binding epidermal growth factor-like growth factor can induce proliferation, as well as inhibit the adipogenic, chondrogenic and osteogenic differentiation of ESCs (43). In the present study, enrichment analysis for genes in the FI network revealed that $E G F$ was enriched in the Ras $(\mathrm{K})$ and Rap1 signaling pathways (K). These results suggested that $H N F 4 A$ and $E G F$ may also be implicated in the differentiation of iPSCs into hepatocytes.

In conclusion, in the present study, a comprehensive bioinformatics analysis was performed to investigate the mechanisms involved in the differentiation of iPSCs to hepatocytes. A total of 433 and 1,342 DEGs were identified in T5 and T24 samples respectively, compared with T0 samples. The results indicated that $F G F 2, B M P 2, C D K 1, H N F 4 A$ and $E G F$ may participate in the differentiation of iPSCs into hepatocytes. However, further experiments are required to elucidate their exact roles in the generation of hepatocytes from iPSCs.

\section{References}

1. Kim K, Doi A, Wen B, Ng K, Zhao R, Cahan P, Kim J, Aryee MJ, Ji H, Ehrlich LI, et al: Epigenetic memory in induced pluripotent stem cells. Nature 467: 285-290, 2010.

2. Yu J, Vodyanik MA, Smuga-Otto K, Antosiewicz-Bourget J, Frane JL, Tian S, Nie J, Jonsdottir GA, Ruotti V, Stewart R, et al: Induced pluripotent stem cell lines derived from human somatic cells. Science 318: 1917-1920, 2007.

3. Takahashi K, Tanabe K, Ohnuki M, Narita M, Ichisaka T, Tomoda $\mathrm{K}$ and Yamanaka S: Induction of pluripotent stem cells from adult human fibroblasts by defined factors. Cell 131: 861-872, 2007.

4. Park IH, Zhao R, West JA, Yabuuchi A, Huo H, Ince TA, Lerou PH, Lensch MW and Daley GQ: Reprogramming of human somatic cells to pluripotency with defined factors. Nature 451: 141-146, 2008. 
5. Zheng YW, Ohkohchi N and Taniguchi H: Quantitative evaluation of long-term liver repopulation and the reconstitution of bile ductules after hepatocellular transplantation. World J Gastroenterol 11: 6176-6181, 2005

6. Chen YF, Tseng CY, Wang HW, Kuo HC, Yang VW and Lee OK: Rapid generation of mature hepatocyte-like cells from human induced pluripotent stem cells by an efficient three-step protocol. Hepatology 55: 1193-1203, 2012.

7. Liu H, Kim Y, Sharkis S, Marchionni L and Jang YY: In vivo liver regeneration potential of human induced pluripotent stem cells from diverse origins. Sci Transl Med 3: 82ra39, 2011.

8. Si-Tayeb K, Noto FK, Nagaoka M, Li J, Battle MA, Duris C, North PE, Dalton S and Duncan SA: Highly efficient generation of human hepatocyte-like cells from induced pluripotent stem cells. Hepatology 51: 297-305, 2010

9. Di Bernardini E, Campagnolo P, Margariti A, Zampetaki A, Karamariti E, Hu Y and Xu Q: Endothelial lineage differentiation from induced pluripotent stem cells is regulated by microRNA-21 and transforming growth factor $\beta 2$ (TGF- $\beta 2$ ) pathways. J Biol Chem 289: 3383-3393, 2014

10. Li L, Bennett SA and Wang L: Role of E-cadherin and other cell adhesion molecules in survival and differentiation of human pluripotent stem cells. Cell Adh Migr 6: 59-70, 2012.

11. Chen HF, Chuang CY, Lee WC, Huang HP, Wu HC, Ho HN, Chen YJ and Kuo HC: Surface marker epithelial cell adhesion molecule and E-cadherin facilitate the identification and selection of induced pluripotent stem cells. Stem Cell Rev 7: 722-735, 2011.

12. Takayama K, Inamura M, Kawabata K, Katayama K, Higuchi M, Tashiro K, Nonaka A, Sakurai F, Hayakawa T, Furue MK and Mizuguchi H: Efficient generation of functional hepatocytes from human embryonic stem cells and induced pluripotent stem cells by $\mathrm{HNF} 4 \alpha$ transduction. Mol Ther 20: 127-137, 2012.

13. Bernardo AS, Faial T, Gardner L, Niakan KK, Ortmann D, Senner CE, Callery EM, Trotter MW, Hemberger M, Smith JC, et al: BRACHYURY and CDX2 mediate BMP-induced differentiation of human and mouse pluripotent stem cells into embryonic and extraembryonic lineages. Cell Stem Cell 9: 144-155, 2011

14. Wilson AA, Ying L, Liesa M, Segeritz CP, Mills JA, Shen SS, Jean J, Lonza GC, Liberti DC, Lang AH, et al: Emergence of a stage-dependent human liver disease signature with directed differentiation of alpha-1 antitrypsin-deficient iPS cells. Stem Cell Reports 4: 873-885, 2015.

15. Irizarry RA, Hobbs B, Collin F, Beazer-Barclay YD, Antonellis KJ, Scherf U and Speed TP: Exploration, normalization, and summaries of high density oligonucleotide array probe level data. Biostatistics 4: 249-264, 2003.

16. Carlson M, Falcon S, Pages H and Li N: org. Hs. eg. db: Genome wide annotation for Human. R package version, 2013

17. MacDonald JW: hugene10sttranscriptcluster.db: Affymetrix hugene10 annotation data (chip hugene10sttranscriptcluster). R package version 8.4.0, 2016.

18. Smyth GK: Limma: linear models for microarray data. In: Bioinformatics and computational biology solutions using $\mathrm{R}$ and Bioconductor. Springer, New York, NY, pp397-420, 2005.

19. Benjamini $Y$ and Hochberg $Y$ : Controlling the false discovery rate: A practical and powerful approach to multiple testing. Journal of the royal statistical society. Series B (Methodological) 57: 289-300, 1995.

20. Chen J, Bardes EE, Aronow BJ and Jegga AG: ToppGene Suite for gene list enrichment analysis and candidate gene prioritization. Nucleic Acids Res 37 (Web Server issue): W305-W311, 2009.

21. Harris MA, Clark J, Ireland A, Lomax J, Ashburner M, Foulger R, Eilbeck K, Lewis S, Marshall B, Mungall C, et al: The gene ontology (GO) database and informatics resource. Nucleic Acids Res 32 (Database issue): D258-D261, 2004

22. Kanehisa M, Araki M, Goto S, Hattori M, Hirakawa M, Itoh M, Katayama T, Kawashima S, Okuda S, Tokimatsu T and Yamanishi Y: KEGG for linking genomes to life and the environment. Nucleic Acids Res 36 (Database issue): D480-D484, 2008

23. Langfelder P and Horvath S: WGCNA: An R package for weighted correlation network analysis. BMC Bioinformatics 9 : $559,2008$.

24. Szklarczyk D, Franceschini A, Kuhn M, Simonovic M, Roth A, Minguez P, Doerks T, Stark M, Muller J, Bork P, et al: The STRING database in 2011: Functional interaction networks of proteins, globally integrated and scored. Nucleic Acids Res 39 (Database issue): D561-D568, 2011.
25. Saito R, Smoot ME, Ono K, Ruscheinski J, Wang PL, Lotia S, Pico AR, Bader GD and Ideker T: A travel guide to Cytoscape plugins. Nat Methods 9: 1069-1076, 2012.

26. Wu G, Dawson E, Duong A, Haw R and Stein L: ReactomeFIViz: A Cytoscape app for pathway and network-based data analysis Version 2. F1000Res 3: 146, 2014.

27. Eiselleova L, Matulka K, Kriz V, Kunova M, Schmidtova Z, Neradil J, Tichy B, Dvorakova D, Pospisilova S, Hampl A and Dvorak P: A complex role for FGF-2 in self-renewal, survival, and adhesion of human embryonic stem cells. Stem Cells 27: 1847-1857, 2009.

28. Diecke S, Quiroga-Negreira A, Redmer T and Besser D: FGF2 signaling in mouse embryonic fibroblasts is crucial for self-renewal of embryonic stem cells. Cells Tissues Organs 188: 52-61, 2008.

29. Yu P, Pan G, Yu J and Thomson JA: FGF2 sustains NANOG and switches the outcome of BMP4-induced human embryonic stem cell differentiation. Cell Stem Cell 8: 326-334, 2011.

30. Pera MF, Andrade J, Houssami S, Reubinoff B, Trounson A, Stanley EG, Ward-van Oostwaard D and Mummery C: Regulation of human embryonic stem cell differentiation by BMP-2 and its antagonist noggin. J Cell Sci 117: 1269-1280, 2004.

31. Valera E, Isaacs MJ, Kawakami Y, Izpisúa Belmonte JC and Choe S: BMP-2/6 heterodimer is more effective than BMP-2 or BMP-6 homodimers as inductor of differentiation of human embryonic stem cells. PLoS One 5: e11167, 2010.

32. Sudheer S, Bhushan R, Fauler B, Lehrach H and Adjaye J: FGF inhibition directs BMP4-mediated differentiation of human embryonic stem cells to syncytiotrophoblast. Stem Cells Dev 21: 2987-3000, 2012.

33. Wei Y, Chen YH, Li LY, Lang J, Yeh SP, Shi B, Yang CC, Yang JY, Lin CY, Lai CC and Hung MC: CDK1-dependent phosphorylation of EZH2 suppresses methylation of $\mathrm{H} 3 \mathrm{~K} 27$ and promotes osteogenic differentiation of human mesenchymal stem cells. Nat Cell Biol 13: 87-94, 2011.

34. Li L, Wang J, Hou J, Wu Z, Zhuang Y, Lu M, Zhang Y, Zhou X, Li Z, Xiao W and Zhang W: Cdk1 interplays with Oct4 to repress differentiation of embryonic stem cells into trophectoderm. FEBS Lett 586: 4100-4107, 2012

35. Ullah Z, Kohn MJ, Yagi R, Vassilev LT and DePamphilis ML: Differentiation of trophoblast stem cells into giant cells is triggered by p57/Kip2 inhibition of CDK1 activity. Genes Dev 22: 3024-3036, 2008.

36. Van Hoof D, Muñoz J, Braam SR, Pinkse MW, Linding R, Heck AJ, Mummery CL and Krijgsveld J: Phosphorylation dynamics during early differentiation of human embryonic stem cells. Cell Stem Cell 5: 214-226, 2009.

37. Zhang WW, Zhang XJ, Liu HX, Chen J, Ren YH, Huang DG, Zou XH and Xiao W: Cdk1 is required for the self-renewal of mouse embryonic stem cells. J Cell Biochem 112: 942-948, 2011

38. DeLaForest A, Nagaoka M, Si-Tayeb K, Noto FK, Konopka G, Battle MA and Duncan SA: HNF4A is essential for specification of hepatic progenitors from human pluripotent stem cells. Development 138: 4143-4153, 2011

39. Deng XG, Qiu RL, Wu YH, Li ZX, Xie P, Zhang J, Zhou JJ, Zeng LX, Tang J, Maharjan A and Deng JM: Overexpression of miR-122 promotes the hepatic differentiation and maturation of mouse ESCs through a miR-122/FoxA1/HNF4a-positive feedback loop. Liver Int 34: 281-295, 2014.

40. Liu T, Zhang S, Xiang D and Wang Y: Induction of hepatocyte-like cells from mouse embryonic stem cells by lentivirus-mediated constitutive expression of Foxa2/Hnf4a. J Cell Biochem 114: 2531-2541, 2013.

41. Heo JS, Lee YJ and Han HJ: EGF stimulates proliferation of mouse embryonic stem cells: Involvement of $\mathrm{Ca} 2+$ influx and p44/42 MAPKs. Am J Physiol Cell Physiol 290: C123-C133, 2006.

42. Park $\mathrm{JH}$ and Han $\mathrm{HJ}$ : Caveolin-1 plays important role in EGF-induced migration and proliferation of mouse embryonic stem cells: Involvement of PI3K/Akt and ERK. Am J Physiol Cell Physiol 297: C935-C944, 2009.

43. Krampera M, Pasini A, Rigo A, Scupoli MT, Tecchio C, Malpeli G, Scarpa A, Dazzi F, Pizzolo G and Vinante F: HB-EGF/HER-1 signaling in bone marrow mesenchymal stem cells: Inducing cell expansion and reversibly preventing multilineage differentiation. Blood 106: 59-66, 2005.

This work is licensed under a Creative Commons Attribution-NonCommercial-NoDerivatives 4.0 International (CC BY-NC-ND 4.0) License. 